\title{
BMJ
}

\section{Association of cerebral palsy with Apgar score in low and normal birthweight infants: population based cohort study}

\author{
Kari Kveim Lie, senior researcher, ${ }^{1}$ Else-Karin Grøholt, senior researcher, ${ }^{1}$ Anne Eskild, professor ${ }^{2,3}$
}

\begin{abstract}
'Division of Epidemiology,
Norwegian Institute of Public

Health, Oslo, Norway

${ }^{2}$ Department of Obstetrics and

Gynaecology and Medical Faculty

Division, Akershus University

Hospital, Nordbyhagen, Norway

${ }^{3}$ Division of Mental Health,

Norwegian Institute of Public

Health, Oslo, Norway

Correspondence to: K Kveim Lie,

Division of Epidemiology,

Norwegian Institute of Public

Health, PO Box 4404, Nydalen,

0403 Oslo, Norway

kari.kveim.lie@fhi.no
\end{abstract}

Cite this as: BMJ 2010;341:C4990 doi:10.1136/bmj.c4990

\section{ABSTRACT}

Objectives To assess the association of Apgar score 5 minutes after birth with cerebral palsy in both normal weight and low birthweight children, and also the association with the cerebral palsy subdiagnoses of quadriplegia, diplegia, and hemiplegia.

Design Population based cohort study.

Setting The Medical Birth Registry of Norway was used to identify all babies born between 1986 and 1995 . These data were linked to the Norwegian Registry of Cerebral Palsy in Children born 1986-95, which was established on the basis of discharge diagnoses at all paediatric departments in Norway.

Population All singletons without malformations born in Norway during 1986-95 and who survived the first year of life $(n=543064)$.

Main outcome measure Cerebral palsy diagnosed before the age of 5 years.

Results 988 children (1.8 in 1000) were diagnosed with cerebral palsy before the age of 5 years. In total, 11\% (39/ 369) of the children with Apgar score of less than 3 at birth were diagnosed with cerebral palsy, compared with only $0.1 \%(162 / 179515)$ of the children with Apgar score of 10 (odds ratio (OR) 53, 95\% Cl 35 to 80 after adjustment for birth weight). In children with a birth weight of $2500 \mathrm{~g}$ or more, those with an Apgar score of less than 4 were much more likely to have cerebral palsy than those who had an Apgar score of more than 8 (OR 125, 95\% confidence interval 91 to 170). The corresponding OR in children weighing less than $1500 \mathrm{~g}$ was 5 (95\% Cl 2 to 9). Among children with Apgar score of less than 4, 10-17\% in all birthweight groups developed cerebral palsy. Low Apgar score was strongly associated with each of the three subgroups of spastic cerebral palsy, although the association was strongest for quadriplegia (adjusted OR 137 for Apgar score $<4$ vApgar score $>8,95 \% \mathrm{Cl} 77$ to 244).

Conclusions Low Apgar score was strongly associated with cerebral palsy. This association was high in children with normal birth weight and modest in children with low birth weight. The strength of the association differed between subgroups of spastic cerebral palsy. Given that Apgar score is a measure of vitality shortly after birth, our findings suggest that the causes of cerebral palsy are closely linked to factors that reduce infant vitality.

\section{INTRODUCTION}

In Western countries, cerebral palsy is diagnosed in two to three infants in every 1000 live born children. ${ }^{12}$ Cerebral palsy is diagnosed on the basis of clinical symptoms only and is defined as "a group of permanent disorders of the development of movement and posture, causing activity limitation, that are attributed to non-progressive disturbances that occurred in the developing foetal or infant brain." ${ }^{3}$ Perinatal hypoxia was previously considered the major cause of cerebral palsy, whereas current knowledge suggests that prenatal causes are most important. ${ }^{12}$ Given that the causes of cerebral palsy remain largely unknown, epidemiological studies in well defined populations are called for.

Apgar score is a measure of the vitality of the newborn infant on the basis of heart rate, respiration, colour, muscle tone, and reflex irritability. ${ }^{4}$ An association between low Apgar score and cerebral palsy was first thoroughly described in $1981,{ }^{5}$ but has since been debated..$^{6-8}$ More recent studies have found a strong association between low Apgar score and cerebral palsy in children born to term or with normal birth weight, ${ }^{910}$ whereas studies in children with a low birth weight or born preterm have shown conflicting results. ${ }^{1-17}$ Low birth weight and immaturity are closely related to the risk of cerebral palsy ${ }^{1}$ and are also associated with a low Apgar score. ${ }^{18}$ However, whether low Apgar score is associated with cerebral palsy, independent of birth weight, has not been studied to our knowledge.

Understanding the association between Apgar score and cerebral palsy in children with normal or low birth weight could increase our comprehension of differences in the causal pathways to cerebral palsy between the different subgroups of the disease. In order to gain such knowledge, studies with uniform design and diagnostic routines independent of birth weight are required. We aimed to estimate in a cohort of more than half a million children the association of Apgar score 5 minutes after birth with cerebral palsy in both normal birthweight and low birthweight children. We also studied the association of Apgar score and birth weight with the main subdiagnoses of spastic cerebral palsy: quadriplegia, diplegia, and hemiplegia. 
Table 1|Prevalence and odds of cerebral palsy according to Apgar score 5 minutes after birth and birth weight

\begin{tabular}{|c|c|c|c|}
\hline & $\begin{array}{l}\text { Prevalence of cerebral palsy } \\
\qquad(\mathrm{n} / \mathrm{N}(\%))\end{array}$ & $\begin{array}{l}\text { Crude odds ratio } \\
\qquad(95 \% \mathrm{Cl})\end{array}$ & $\begin{array}{c}\text { Adjusted odds ratio } \\
(95 \% \mathrm{Cl})\end{array}$ \\
\hline \multicolumn{4}{|l|}{ Apgar score } \\
\hline$\ll 3$ & $39 / 369(10.6)$ & 130.8 (90.8 to188.6) & 53.1 (35.2 to 79.9$)$ \\
\hline 3 & $29 / 268(10.8)$ & 134.3 (88.7 to 203.4 ) & 49.5 (31.2 to 78.6$)$ \\
\hline 4 & $39 / 445(8.8)$ & 106.3 (74.0 to 152.9$)$ & $34.7(23.1$ to 52.1$)$ \\
\hline 5 & $34 / 964$ (3.5) & 40.5 (27.8 to 58.9$)$ & 12.6 (8.4 to 18.8$)$ \\
\hline 6 & $47 / 2150(2.2)$ & 24.7 (17.8 to 34.3$)$ & 8.3 (5.9 to 11.8 ) \\
\hline 7 & $79 / 4716(1.7)$ & 18.9 (14.4 to 24.7$)$ & 7.0 (5.2 to 9.3$)$ \\
\hline 8 & $128 / 16536(0.8)$ & 8.6 (6.8 to 10.9$)$ & 4.4 (3.5 to 5.7$)$ \\
\hline 9 & 431/338101 (0.1) & 1.4 (1.2 to 1.7$)$ & 1.3 (1.1 to 1.6$)$ \\
\hline 10 & $162 / 179515(0.1)$ & Reference & Reference \\
\hline \multicolumn{4}{|c|}{ Birth weight (g) } \\
\hline$<1000$ & $60 / 670(9.1)$ & $106.5(78.7$ to 144.2$)$ & 20.5 (14.5 to 28.9 ) \\
\hline $1000-1499$ & $133 / 1959(6.8)$ & 78.9 (62.7 to 99.2) & $27.5(21.3$ to 35.5$)$ \\
\hline 1500-1999 & $96 / 3891(2.5)$ & 27.4 (21.3 to 35.2$)$ & $14.5(11.1$ to 18.8$)$ \\
\hline 2000-2499 & $95 / 11466(0.8)$ & 9.0 (7.1 to 11.6$)$ & $6.2(4.3$ to 8.1$)$ \\
\hline 2500-2999 & $105 / 54659(0.2)$ & 2.1 (1.6 to 2.7 ) & 1.9 (1.5 to 2.4$)$ \\
\hline $3000-3499$ & $220 / 169538(0.1)$ & $1.4(1.2$ to 1.7$)$ & $1.4(1.1$ to 1.7$)$ \\
\hline 3500-3999 & 179/194 $035(0.1)$ & Reference & Reference \\
\hline 4000-4999 & $97 / 104486(0.1)$ & $1.0(0.8$ to 1.3$)$ & $1.0(0.8$ to 1.2$)$ \\
\hline$\geq 5000$ & $3 / 2360(0.1)$ & $1.4(0.4$ to 4.3$)$ & 1.1 (0.3 to 3.4) \\
\hline
\end{tabular}

\section{METHODS}

Design

We performed a population based cohort study by linking data in the following Norwegian registries: the Medical Birth Registry; the Cause of Death Registry; and the Registry of Cerebral Palsy in children born 1986-95.

\section{Study population}

Our study population included all children who were born in Norway 1986-95 and had survived the first year of life $(n=581360)$. Children born in multiple pregnancies $(\mathrm{n}=14533)$ and children with congenital malformations ( $n=17766$ ) were excluded from the study. Children for whom information on birth weight, Apgar score, or both was not available were also excluded $(\mathrm{n}=6413(1 \%))$; hence, our study sample consisted of 543064 children.

\section{Data collection and study factors}

Study participants were identified through the Norwegian Medical Birth Registry, which by law includes all births in Norway after 16 weeks of gestation. ${ }^{19}$ Information on death during the first year of life was obtained through linkage to the Cause of Death Registry, Statistics Norway. Information on cerebral palsy was obtained by linking these data to the Norwegian Registry of Cerebral Palsy in children born 1986-95 by using the unique person identification number given to all children in Norway shortly after birth. This cerebral palsy registry was established on the basis of discharge diagnoses issued during 1988-2001 from all hospitals with a paediatric department in Norway. Hence, children in the cohort who had been diagnosed with cerebral palsy before the age of 5 could be identified.

Once all children diagnosed with cerebral palsy at the different centres by the end of 2001 had been identified, their data were merged into one cerebral palsy registry and overlapping registrations were deleted All children had been diagnosed by a paediatrician specially trained in child neurology. The diagnosis of cerebral palsy, either as a primary or secondary diagnosis, was classified according to the international classification of diseases, 9th revision (codes 343.0-3 and 89 ) or the international classification of diseases, 10th revision (codes G.80.0-9). Information on the cerebral palsy subdiagnoses hemiplegia (code 343.1), diplegia (code 343.0), and quadriplegia (code 343.2) was obtained in children diagnosed according to the international classification of diseases, 9 th revision, only. If a child was registered with more than one cerebral palsy subdiagnosis, the most recent diagnosis was chosen. Children with reported postnatal origin of cerebral palsy were not included.

Apgar score 5 minutes after birth (hereafter "Apgar score") and birth weight were obtained through the Norwegian Medical Birth Registry. Apgar score is a score ranging from 0-10 that consists of five components, each rated on a scale of 0-2: heart rate; respiration; colour; muscle tone; and reflex irritability. ${ }^{4}$ Apgar score is routinely measured by the attending midwife 1 minute and 5 minutes after birth. The attending midwife is also responsible for reporting this information on standardised forms and submitting the data to the Medical Birth Registry, usually within 24 hours of the delivery.

\section{Statistical methods}

In the study sample as a whole, the associations of cerebral palsy with Apgar score and birth weight were estimated as differences in prevalence (\%), and as odds ratios (OR) with 95\% confidence intervals (95\% CI) using logistic regression analyses. Prevalence of cerebral palsy and OR of cerebral palsy according to Apgar score were also estimated for the following birthweight groups: less than $1500 \mathrm{~g} ; 1500-2499 \mathrm{~g}$; and $2500 \mathrm{~g}$ or more. Separate analyses were performed with each cerebral palsy subdiagnosis as the outcome variable. SPSS version 17.0 was used for the data analyses.

\section{RESULTS}

In our study, 988 of the 543064 children included (1.8 in 1000) were diagnosed with cerebral palsy before the age of 5 years. A total of 677 children with cerebral palsy were subclassified according to the international classification of diseases, 9th revision: 127 (19\%) had quadriplegia; 214 (32\%) had diplegia; 222 (33\%) had hemiplegia; and $114(17 \%)$ had another cerebral palsy subdiagnosis or a combination of subdiagnoses.

Apgar score was strongly associated with cerebral palsy (table 1). In total, 11\% (39/369) of the children with an Apgar score of less than 3 were diagnosed with cerebral palsy, compared with only $0.1 \%(162 / 179515)$ of the children with Apgar score of 10. The crude OR of 
Table $2 \mid$ Prevalence and odds of cerebral palsy within birthweight groups according to Apgar score

\begin{tabular}{|c|c|c|}
\hline Apgar score & $\begin{array}{l}\text { Proportion with cerebral palsy } \\
\qquad(\mathrm{n} / \mathrm{N}(\%))\end{array}$ & $\begin{array}{l}\text { Odds ratio } \\
(95 \% \mathrm{Cl})\end{array}$ \\
\hline \multicolumn{3}{|c|}{ Birth weight $<1500 \mathrm{~g}(\mathrm{n}=2629)$} \\
\hline$<4$ & 12/71 (16.9) & $4.6(2.3$ to 9.0$)$ \\
\hline $4-6$ & $35 / 349(10.0)$ & 2.5 (1.6 to 3.9) \\
\hline 7-8 & 90/887 (10.1) & $2.6(1.8$ to 3.6$)$ \\
\hline 18 & $56 / 1322(4.2)$ & Reference \\
\hline \multicolumn{3}{|c|}{ Birth weight $1500-2499 \mathrm{~g}(\mathrm{n}=15357)$} \\
\hline$<4$ & 8/71 (11.3) & 15.7 (7.3 to 33.6$)$ \\
\hline $4-6$ & $21 / 449(4.7)$ & 6.1 (3.8 to 9.8$)$ \\
\hline $7-8$ & $59 / 2012(2.9)$ & 3.7 (2.7 to 5.2$)$ \\
\hline$>8$ & $103 / 12825(0.8)$ & Reference \\
\hline \multicolumn{3}{|c|}{ Birth weight $\geq 2500 \mathrm{~g}(\mathrm{n}=525078)$} \\
\hline$\ll 4$ & 48/495 (9.7) & $124.5(91.1$ to 170.1$)$ \\
\hline 4-6 & $64 / 2761(2.3)$ & 27.5 (21.1 to 35.9) \\
\hline 7-8 & $58 / 18353(0.3)$ & $3.7(2.8$ to 4.8$)$ \\
\hline 18 & $434 / 503469(0.1)$ & Reference \\
\hline
\end{tabular}

being diagnosed with cerebral palsy for children with an Apgar score of less than 3 compared with those who had an Apgar score of 10 was 131 (95\% CI 91 to 189).

Low birth weight was also strongly associated with cerebral palsy (table 1). A total of $9 \%(60 / 670)$ of the children with a birth weight of less than $1000 \mathrm{~g}$ were diagnosed with cerebral palsy, whereas only $0.1 \%$ $(179 / 194035)$ of children weighing 3500-3999 $\mathrm{g}$ at birth received the diagnosis. The crude OR for cerebral palsy when comparing birth weight of less than $1000 \mathrm{~g}$ with birth weight of 3500-3999 $\mathrm{g}$ was 107 (95\% CI 79 to 144$)$.

Apgar score was still strongly linked with cerebral palsy after adjustment for birth weight, although the association was attenuated (OR 53, 95\% CI 35 to 80 , for Apgar score $<3 v$ Apgar score 10). Adjustment for Apgar score likewise attenuated the association between birth weight and cerebral palsy (OR 21, 95\% CI 15 to 29 , for birth weight $<1000 \mathrm{~g} v$ birth weight 3500-3999 g).

Birth weight was associated with both Apgar score and cerebral palsy. Half $(50 \%(1307 / 2629))$ the children with a birth weight of less than $1500 \mathrm{~g}$ had an Apgar score of less than 9, compared with 4\% (21 609/ 525078 ) of the children with birth weight of $2500 \mathrm{~g}$ or more (table 2). In children with a birth weight of less than $1500 \mathrm{~g}, 7 \%$ (193/2629) were diagnosed with cerebral palsy, compared with $0.1 \%(604 / 525078)$ of children with birth weight of $2500 \mathrm{~g}$ or more. In children with birth weight of less than $1500 \mathrm{~g}$, the proportion with cerebral palsy was higher than that in children with a higher birth weight at every level of Apgar score (fig 1). In all birthweight groups, however, 10 17\% of the children with Apgar score of less than 4 were diagnosed with cerebral palsy. The OR of cerebral palsy when comparing Apgar score of less than 4 with Apgar score of more than 8 was much higher in children with birth weight of $2500 \mathrm{~g}$ or more than in children weighing less than $1500 \mathrm{~g}$ (OR 125, 95\% CI 91 to 170 , and OR 5, 95\% CI 2 to 9, respectively; table 2).

The associations of Apgar score and birth weight with cerebral palsy differed between the subdiagnoses quadriplegia, diplegia, and hemiplegia (table 3). Low Apgar score showed the strongest association with quadriplegia. After adjustment for birth weight, the OR of quadriplegia for an Apgar score of less than 4 compared with an Apgar score of more than 8 was 137 (95\% CI 77 to 244). The corresponding ORs for diplegia and hemiplegia were $22(95 \%$ CI 12 to 41$)$ and 10 (95\% CI 4 to 26), respectively. Low birth weight was most strongly associated with diplegia. Comparing children with birth weight less than $1500 \mathrm{~g}$ with children weighing $2500 \mathrm{~g}$ or more, the OR for developing diplegia was 62 (95\% CI 42 to 92) after adjustment for Apgar score. For quadriplegia the corresponding OR was 11 (95\% CI 7 to 18) and for hemiplegia it was 16 (95\% CI 10 to 26$)$.

It should be noted that almost $90 \%$ of the children with Apgar score of less than 4 did not develop cerebral palsy, and among the children with cerebral palsy, 80\% had Apgar score above 6.

\section{DISCUSSION}

\section{Principal findings}

In this population based cohort study, low Apgar score 5 minutes after birth was strongly associated with later diagnosis of cerebral palsy. The prevalence of cerebral palsy in children with Apgar score of less than 3 was more than 130-fold higher than in children with Apgar score of 10. Also, in children of low birth weight, low Apgar score was significantly associated with increased risk of cerebral palsy, although this relation was less pronounced. In children with Apgar score of less than 4 , between $10 \%$ and $17 \%$ in all birthweight groups were diagnosed with cerebral palsy. The association between Apgar score and cerebral palsy was seen for all subgroups of spastic cerebral palsy, but the strength of the association was strongest for quadriplegia.

\section{Interpretation of the findings}

Given that Apgar score is a measure of vitality shortly after birth, our findings suggest that the causes of

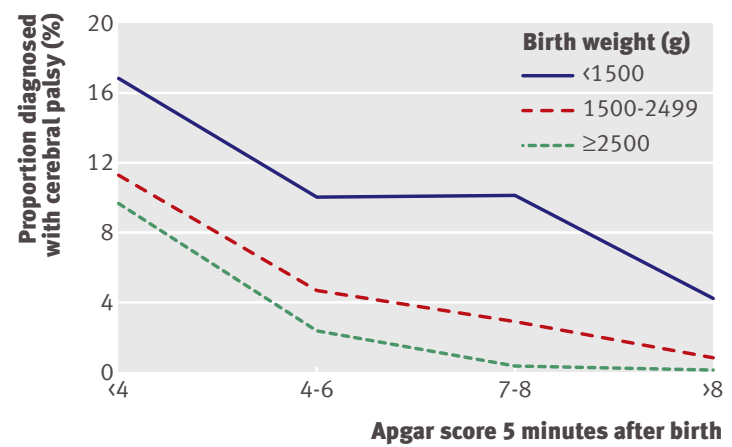

Proportions diagnosed with cerebral palsy according to Apgar score in children with birth weight of less than $1500 \mathrm{~g}, 1500$ $2499 \mathrm{~g}$, and $2500 \mathrm{~g}$ or more 


\begin{tabular}{|c|c|c|c|}
\hline & Number of cases & Crude odds ratio $(95 \% \mathrm{Cl})$ & Adjusted odds ratio $(95 \% \mathrm{Cl})$ \\
\hline \multicolumn{4}{|l|}{ Quadriplegia } \\
\hline \multicolumn{4}{|l|}{ Apgar score } \\
\hline$<4$ & 19 & 269.8 (160.6 to 453.1) & 136.7 (76.6 to 243.7$)$ \\
\hline 4-6 & 30 & 70.5 (45.6 to 108.9$)$ & $35.4(21.5$ to 58.5$)$ \\
\hline 7-8 & 14 & 5.4 (3.0 to 9.6$)$ & $3.7(2.0$ to 6.7$)$ \\
\hline$>8$ & 64 & Reference & Reference \\
\hline \multicolumn{4}{|l|}{ Birth weight (g) } \\
\hline$\ll 1500$ & 28 & $71.8(46.7$ to 110.3$)$ & 11.0 (6.6 to 18.4 ) \\
\hline $1500-2499$ & 15 & 6.2 (3.6 to 10.7$)$ & $3.0(1.7$ to 5.3$)$ \\
\hline$\geq 2500$ & 84 & Reference & Reference \\
\hline
\end{tabular}

\section{Diplegia}

Apgar score

\begin{tabular}{lccc}
\hline 44 & 15 & $125.0(72.4$ to 215.9$)$ & $22.4(12.1$ to 41.1$)$ \\
\hline $4-6$ & 23 & $31.7(20.2$ to 49.8$)$ & $5.8(3.5$ to 9.6$)$ \\
\hline $7-8$ & 67 & $15.1(11.1$ to 20.5$)$ & $4.8(3.4$ to 6.8$)$ \\
\hline 18 & 109 & Reference & Reference \\
\hline
\end{tabular}

\section{Birth weight (g)}

\begin{tabular}{llcc}
$\langle 1500$ & 69 & $176.9(128.3$ to 243.8$)$ & $62.2(42.2$ to 91.8$)$ \\
\hline $1500-2499$ & 61 & $25.1(18.1$ to 34.9$)$ & $17.2(12.2$ to 24.3$)$ \\
$\geq 2500$ & 84 & Reference & Reference \\
\hline
\end{tabular}

\section{Hemiplegia}

Apgar score

\begin{tabular}{cccc}
\hline$<4$ & 5 & $27.7(11.3$ to 67.7$)$ & $10.2(4.0$ to 25.9$)$ \\
\hline $4-6$ & 18 & $16.5(10.1$ to 26.9$)$ & $6.2(3.6$ to 10.5$)$ \\
\hline $7-8$ & 35 & $5.2(3.6$ to 7.6$)$ & $2.9(1.9$ to 4.2$)$ \\
\hline 18 & 164 & Reference & Reference \\
\hline
\end{tabular}

Birth weight (g)

\begin{tabular}{lccc}
\hline 1500 & 26 & $36.8(24.3$ to 55.9$)$ & $16.2(10.0$ to 26.4$)$ \\
\hline $1500-2499$ & 44 & $10.0(7.2$ to 14.0$)$ & $7.7(5.5$ to 11.0$)$ \\
\hline$\geq 2500$ & 152 & Reference & Reference \\
\hline
\end{tabular}

cerebral palsy are closely linked to factors that reduce infant vitality. Low Apgar score was previously regarded as a sign of perinatal asphyxia, but is now considered of limited value for diagnosing asphyxia. ${ }^{8}$ In addition, low Apgar score has been shown to predict infant death far better than low $\mathrm{pH}$ in the umbilical artery. ${ }^{20}$ Hence, factors other than infant asphyxia may be associated with Apgar score and, therefore, with cerebral palsy. Low Apgar score is also linked to immaturity, malformations, and impairments of the central nervous system. ${ }^{182122}$ In fact, low Apgar score might be interpreted as an indicator of brain impairment that has occurred in utero or during delivery. Such interpretation of Apgar score implies that all children with a low Apgar score have a similar risk of cerebral palsy independent of birth weight, which is in accordance with our results. Low Apgar score might, therefore, be considered a marker of underlying causal factors of cerebral palsy. Knowledge of the association of Apgar score with cerebral palsy within subgroups of children could be important in the search for causes.

In children with low birth weight, the prevalence of cerebral palsy was higher than in children with a normal birth weight: 7\% (193/2629) of children with birth weight of less than $1500 \mathrm{~g}$ were diagnosed with cerebral palsy versus $0.1 \%(604 / 525078)$ of children with birth weight of $2500 \mathrm{~g}$ or more. This increased prevalence could be caused by immaturity, which might also be reflected in the high proportion of low birthweight children with an Apgar score of less than 9. Furthermore, an association of low Apgar score with cerebral palsy was found in children with low birth weight. This finding suggests that there might be other factors in addition to immaturity that can cause cerebral palsy in infants with a low birth weight. In fact, the differences in the proportion of infants with cerebral palsy according to Apgar score were greater in low birthweight than in normal birthweight children. Such knowledge may be important in clinical follow-up.

In children with birth weight of $2500 \mathrm{~g}$ or more, the overall prevalence of cerebral palsy was low. Furthermore, normal birthweight infants with cerebral palsy were less likely to have a low Apgar score at birth than were low birthweight infants with cerebral palsy (28\% v $71 \%$ had an Apgar score $<9$ ). This difference suggests that factors not measured by the Apgar score play a larger role in the causes of cerebral palsy in normal birthweight infants than in low birthweight infants.

At every level of Apgar score the prevalence of cerebral palsy was highest in children with a low birth weight; however, the OR of cerebral palsy associated with low Apgar score $(<4)$ was highest in normal weight children. In $50 \%$ of all children with cerebral palsy, neither low birth weight $(<2500 \mathrm{~g})$ nor low Apgar score $(<7)$ were found. These findings support the present understanding that cerebral palsy is a multifactorial disorder. ${ }^{1}$

\section{Strengths and limitations of the study}

Our study included all singleton children who were born in Norway during the years 1986 through 1995, did not have malformations, and were alive at 1 year of age. By obtaining information on infant death from the Cause of Death Registry, we excluded children who died before cerebral palsy could be diagnosed. Selection bias caused by skewed inclusion or follow-up is, therefore, unlikely to have occurred. Information on diagnoses of cerebral palsy was obtained from all paediatric departments in Norway. We believe, therefore, that most children in the cohort with a diagnosis of cerebral palsy were identified and included in the study.

The healthcare system in Norway is homogeneous throughout the country, and medical care is available free of charge for all children younger than 12 years of age. Although diagnosing cerebral palsy, in particular mild cerebral palsy, and subdiagnoses of cerebral palsy can be hard, ${ }^{2324}$ the established network between Norwegian paediatricians working in child neurology facilitates uniform diagnostic practice. The prevalence of cerebral palsy in our study, as well as the distribution of subdiagnoses, is in accordance with other Norwegian studies that include fewer but well characterised cases. ${ }^{2526}$ Cerebral palsy is a rare disease, so despite the possibility of underdiagnosis, in particular for mild cerebral palsy, it seems unlikely that possible 


\section{WHAT IS ALREADY KNOWN ON THIS SUBJECT}

Low Apgar score is strongly associated with cerebral palsy in children born at term; however, the majority of children with a low Apgar score do not develop cerebral palsy

The risk of cerebral palsy is elevated in children with low birth weight

Studies in children with low birth weight have shown conflicting results with respect to any association between Apgar score and cerebral palsy

\section{WHAT THIS STUDY ADDS}

Between $10 \%$ and $17 \%$ of children with an Apgar score of less than 4 were diagnosed with cerebral palsy, independent of birth weight

Low Apgar score was significantly associated with cerebral palsy in children with low birth weight

Low Apgar score was associated with increased risk of quadriplegia, diplegia, and

hemiplegia; however, the association was most pronounced for quadriplegia

under-reporting has substantially biased our estimates. Possible misclassification of cerebral palsy subdiagnoses in our study would diminish rather than increase the differences between groups in the estimated association of cerebral palsy with Apgar score.

Besides low Apgar score and low birth weight, short length of gestation has also shown strong and consistent associations with cerebral palsy. ${ }^{12}$ Birth weight and length of gestation are closely correlated. In preliminary data analyses, we included length of gestation in addition to birth weight, but the association of low Apgar score with cerebral palsy did not change (data not shown). Data on length of gestation were not available for a considerable proportion of infants of low birth weight. Our aim was to study the association of Apgar score with cerebral palsy in low birthweight infants in particular, and not the differential association of birth weight and length of gestation with cerebral palsy. Given that the association of Apgar score with cerebral palsy did not seem to be confounded by length of gestation, and because we had incomplete data on length of gestation, we only used birth weight in the final data analyses.

In our study we chose to focus on the association of Apgar score with cerebral palsy in children who survived the first year of life, because cerebral palsy cannot be diagnosed with high degree of certainty during the first year. We also assumed that the association of Apgar score with cerebral palsy is most relevant for the children who will stay alive.

\section{Comparison with other studies}

To our knowledge, no previous study has shown an association of low Apgar score with cerebral palsy after adjustment for birth weight. Interestingly, the strong association of low Apgar score with cerebral palsy was only partly attenuated after such adjustment, suggesting that factors associated with infant vitality immediately after birth are closely related to the development of cerebral palsy. The strength of the association of low Apgar score with cerebral palsy decreased markedly with decreasing birth weight (table 2). A similar trend, although less pronounced, was shown in the Collaborative Perinatal Project, a large prospective study among children born in the United States in $1959-66 .{ }^{5}$ In that study the relative risk of cerebral palsy when comparing Apgar score of less than 4 with Apgar score of more than 6 was 24 in children with birth weight of more than $2500 \mathrm{~g}$ and 8 in children with birth weight of $2500 \mathrm{~g}$ or less. Comparisons between the studies are difficult, however, because low Apgar score was present 10 times more often among infants in the Collaborative Perinatal Project than in our study.

More recent studies have found strong associations between Apgar score and cerebral palsy in term children. ${ }^{910}$ One study of very preterm children reported a similar association between cerebral palsy and Apgar score as in our study. ${ }^{14}$ Other studies of low birthweight or preterm children have reported non-significant or weak associations of Apgar score with cerebral palsy. ${ }^{11-13}{ }^{15-17}$ However, most previous studies had low statistical power or included all liveborn children in their follow-up. Low Apgar score, but also low birth weight, is associated with increased infant mortality. ${ }^{2027}$ Given that children who die during the first year of life are unlikely to be diagnosed with cerebral palsy, the association of Apgar score with cerebral palsy may have been underestimated in studies that included these children. When we included the children who died during the first year of life in the analyses, the association of Apgar score with cerebral palsy was no longer significant in children who weighed less than $1500 \mathrm{~g}$ at birth (data not shown). In this group, $81 \%(310 / 381)$ of the infants with an Apgar score of less than 4 died. However, if a larger proportion of children with low Apgar score had survived and thereby had been at risk of being diagnosed with cerebral palsy, the association of Apgar score with cerebral palsy may have been even stronger than presented.

It has been claimed that quadriplegia is the only spastic subdiagnosis of cerebral palsy associated with Apgar score. ${ }^{828}$ Our study suggests strong associations between low Apgar score and the three subdiagnoses of spastic cerebral palsy studied, which persisted after adjustment for birth weight. The association was, however, much stronger for quadriplegia than for diplegia and hemiplegia. The differential associations of Apgar score and birth weight with the various subdiagnosis of cerebral palsy indicate differences in causal pathways. The abandonment of diplegia and quadriplegia as two separate subdiagnoses might, therefore, be challenged on the basis of our findings. ${ }^{3}$

\section{Conclusion}

We found a strong association between low Apgar score 5 minutes after birth and later diagnosis of cerebral palsy. Low Apgar score also was associated with cerebral palsy in children of low birth weight, although this relation was less pronounced than in children of normal birth weight. Despite the strong association of low Apgar score with cerebral palsy, it is encouraging that almost $90 \%$ of children with an Apgar score of less than 4 at birth did not develop cerebral palsy. 
We thank the chief medical officers at the paediatric departments in Norway for providing diagnostic information on children with cerebral palsy.

Contributors: KKL and AE planned the study. KKL established the Norwegian Registry of Cerebral Palsy in children born 1986-95. KKL and $\mathrm{E}-\mathrm{KG}$ performed the analysis, and $\mathrm{KKL}$ and $\mathrm{AE}$ wrote the majority of the paper. KKL, AE, and E-KG discussed the design, edited the paper, and agreed on the final version. KKL is guarantor. All authors had full access to all of the data (including statistical reports and tables) in the study and can take responsibility for the integrity of the data and the accuracy of the data analysis.

Funding: The study was funded by the Norwegian Foundation for Health and Rehabilitation, which had no role in the study planning, data collection, or analysis, or in the writing the article or in the decision to submit the article for publication.

Competing interests: All authors have completed the Unified Competing Interest form at www.icmje.org/coi_disclosure.pdf (available on request from the corresponding author) and declare: no support from any organisation for the submitted work; no financial relationships with any companies that might have an interest in the submitted work in the previous 3 years; no other relationships or activities that could appear to have influenced the submitted work

Ethical approval: The study was approved by the Norwegian Board of Health, the Norwegian Data Inspectorate, and the Regional Committee for Medical Research Ethics.

Data sharing: No additional data available.

1 Stanley F, Blair E, Alberman E. Cerebral palsies: epidemiology and causal pathways. MacKeith Press, 2000.

2 Krageloh-Mann I, Cans C. Cerebral palsy update. Brain Dev 2009;31:537-44

3 Rosenbaum P, Paneth N, Leviton A, Goldstein M, Bax M, Damiano D, et al. A report: the definition and classification of cerebral palsy April 2006. Dev Med Child Neurol Suppl 2007;109:8-14.

4 Apgar V. A proposal for a new method of evaluation of the newborn infant. Curr Res Anesth Analg 1953;32:260-7.

5 Nelson KB, Ellenberg JH. Apgar scores as predictors of chronic neurologic disability. Pediatrics 1981;68:36-44.

6 Blair E, Stanley FJ. Intrapartum asphyxia: a rare cause of cerebral palsy. J Pediatr 1988;112:515-9.

7 Use and abuse of the Apgar score. Committee on Fetus and Newborn, American Academy of Pediatrics, and Committee on Obstetric Practice, American College of Obstetricians and Gynecologists. Pediatrics 1996;98:141-2.

8 American Academy of Pediatrics, Committee on Fetus and Newborn, American College of Obstetricians and Gynecologists, Committee on Obstetric Practice. The Apgar Score. Pediatrics 2006;117:1444-7.

9 Moster D, Lie RT, Irgens LM, Bjerkedal T, Markestad T. The association of Apgar score with subsequent death and cerebral palsy: a population-based study in term infants. J Pediatr 2001;138:798-803.

10 Thorngren-Jerneck K, Herbst A. Perinatal factors associated with cerebral palsy in children born in Sweden. Obstet Gynecol 2006;108:1499-505
11 O'Shea TM, Klinepeter KL, Dillard RG. Prenatal events and the risk of cerebral palsy in very low birth weight infants. Am J Epidemiol 1998;147:362-9.

12 Grether JK, Nelson KB, Emery ES III, Cummins SK. Prenatal and perinatal factors and cerebral palsy in very low birth weight infants. Pediatr 1996;128:407-14.

13 Topp M, Langhoff-Roos J, Uldall P. Preterm birth and cerebral palsy. Predictive value of pregnancy complications, mode of delivery, and Apgar scores. Acta Obstet Gynecol Scand 1997;76:843-8.

14 Murphy DJ, Sellers S, MacKenzie IZ, Yudkin PL, Johnson AM. Casecontrol study of antenatal and intrapartum risk factors for cerebral palsy in very preterm singleton babies. Lancet 1995;346:1449-54.

15 Tran U, Gray PH, O'Callaghan MJ. Neonatal antecedents for cerebral palsy in extremely preterm babies and interaction with maternal factors. Early Hum Dev 2005;81:555-61.

16 Jacobsson B, Hagberg G, Hagberg B, Ladfors L, Niklasson A, Hagberg H. Cerebral palsy in preterm infants: a population-based case-control study of antenatal and intrapartal risk factors. Acto Paediatr 2002;91:946-51.

17 Walstab JE, Bell RJ, Reddihough DS, Brennecke SP, Bessell CK, Beischer NA. Factors identified during the neonatal period associated with risk of cerebral palsy. Aust N Z J Obstet Gynaecol 2004; 44:342-6

18 Hegyi T, Carbone T, Anwar M, Ostfeld B, Hiatt M, Koons A, et al. The Apgar score and its components in the preterm infant. Pediatrics 1998;101:t-81.

19 Irgens LM. The Medical Birth Registry of Norway. Epidemiological research and surveillance throughout 30 years. Acta Obstet Gynecol Scand 2000;79:435-9.

20 Casey BM, McIntire DD, Leveno KJ. The continuing value of the Apgar score for the assessment of newborn infants. $N$ Engl J Med 2001;344:467-71.

21 Catlin EA, Carpenter MW, Brann BS, Mayfield SR, Shaul PW, Goldstein $M$, et al. The Apgar score revisited: influence of gestational age. J Pediatr 1986;109:865-8.

22 Pinheiro JM. The Apgar cycle: a new view of a familiar scoring system. Arch Dis Child Fetal Neonatal Ed 2009;94:F70-2.

23 Gainsborough M, Surman G, Maestri G, Colver A, Cans C. Validity and reliability of the guidelines of the Surveillance of Cerebral Palsy in Europe for the classification of cerebral palsy. Dev Med Child Neurol 2008;50:828-31.

24 Himpens E, Van den Broeck C, Oostra A, Calders P,

Vanhaesebrouck P. Prevalence, type, distribution, and severity of cerebral palsy in relation to gestational age: a meta-analytic review. Dev Med Child Neurol 2008;50:334-40.

25 Meberg A, Broch H. Etiology of cerebral palsy. J Perinat Med 2004;32:434-9.

26 Andersen GL, Irgens LM, Haagaas I, Skranes JS, Meberg AE, Vik T. Cerebral palsy in Norway: prevalence, subtypes and severity. Eur I Paediatr Neurol 2008;12:4-13.

27 Behnke M, Carter RL, Hardt NS, Eyler FD, Cruz AC, Resnick MB. The relationship of Apgar scores, gestational age, and birthweight to survival of low-birthweight infants. Am J Perinatol 1987;4:121-4.

28 MacLennan A. A template for defining a causal relation between acute intrapartum events and cerebral palsy: international consensus statement. BMJ 1999;319:1054-9.

Accepted: 23 July 2010 